\title{
Estimating pedestrian demand for active transport evaluation and planning
}

Dr Ashley Dhanani (corresponding author) ashley.dhanani@ucl.ac.uk

Research Associate

Bartlett School of Architecture, University College London

22 Gordon St, Bloomsbury, London WC1H OQB, UK

Dr Lusine Tarkhanyan

lusine.tarkhanyan@ucl.ac.uk

Research Associate

Bartlett School of Architecture, University College London 22 Gordon St, Bloomsbury, London WC1H 0QB, UK

Professor Laura Vaughan

I.vaughan@ucl.ac.uk

Director, Space Syntax Laboratory

Bartlett School of Architecture, University College London

22 Gordon St, Bloomsbury, London WC1H OQB, UK 


\section{Abstract}

This article presents a recently developed walkability-based approach to evaluating the built environment's relationship to pedestrian activity, as well as the application of this evaluation in generating a model of pedestrian demand across London derived from built environment indicators. The approach is novel in its integration of space syntax measures to evaluate network accessibility and the use of volume area ratios to measure land use intensity. It utilises high-resolution geographic data surfaces for the generation of the built environment variables. The advantage of using this method is that it allows greater analytical flexibility in transport policy and practice, where the ability to compare the analytical results to other social and spatial indicators is vital for decision-making. Pedestrian density data covering the whole of Greater London are used to test the performance of the variables. The best performing variables are then analysed to determine their weighting in a model of pedestrian demand for London based on the selected built environment indicators. Randomised testing shows that the model is capable of reliably predicting pedestrian demand. It can be used to estimate pedestrian demand both currently and for future scenarios by quantify future changes to the built environment, and thus enabling walking to be quantitatively assessed in the same way as motorised modes. The model can be applied to active travel infrastructure planning and policy evaluation, from the scale of the street or intersection, to larger administrative units. The model also has wider theoretical and policy implications that relate to the spatial structuring of London.

\section{Keywords}

Pedestrian Demand; Walkability, Active Transport; Space Syntax; London

\section{Introduction}

This article presents an approach to estimating pedestrian demand in urban environments based on walkability study approaches that allows the inclusion of a range of field-based observations and spatial datasets, with the model functioning both as an exploratory research tool and as an application to be used in urban design and planning - whether to plan infrastructural or behavioural interventions, identify potential community severance, or to assess town centre vitality. The approach diverges from other walkability analysis in that the model is not constrained by geographic or administrative boundaries; instead, the spatial components of the model are interpolated as continually varying surfaces across the entire urban area being studied. This not only enables statistical cross-comparison between multiple datasets, but better visualisation - and so communication of the model to key stakeholders.

Whilst there have been many studies (Van Holle, et al. 2014; Moran et al. 2014; Hajna et al. 2015; McGrath et al. 2015; Leslie et al., 2007; Cerin et al. 2006) carried out that show how certain features of the built environment are associated with differentials in the level of physical activity, and associated health outcomes, that occur in a population living in a particular location, they do not generally seek to provide ways of evaluating the intensity of walking activity likely to take place in a specific location, nor do they provide methods of transferring this research into design tools that can be used by those engaged in transport planning. For example, planners might wish to identify areas that lack adequate pedestrian facilities on the ground in areas which could potentially be attractive to people on foot, or to maximise the active transport - either by improving the design of an area's walking and cycling network infrastructure - or through behavioural change interventions. Currently, there is a lack of evidenced-based tools to do such assessments.

In this article approaches to measuring walkability are examined, including the discussion of the impact of street network on walking activity levels. Four themes of built environment measures are explored: land use characteristics, street network structure, transport accessibility and residential population density. From these four categories, the highest performing built environment variables are selected based on their correspondence to a pedestrian activity dataset. These are then modelled against measured pedestrian activity in order to estimate a weighted model of pedestrian demand based on the built environment indicators. This paper ends with a discussion of the applicability of the model for pedestrian 
demand. This is then widened out to highlight the relevance to this work to theories of travel behaviour and urban spatial structure. The purpose of the presented research is to enable policy and practice to effectively understand and increase active travel, supported by robust quantitative pedestrian demand modelling.

\section{Background}

\section{Walkability and built environment characteristics}

Measuring the walkability of urban environments by analysing and evaluating physical environmental characteristics has gained wide acceptance as a method for assessing the urban environment's potential for encouraging or inhibiting walking (Renalds et al. 2010; Feng et al. 2010), as well as other active transport modes. Walkability models are used widely in transport and health research domains (Freeman et al. 2013; Glazier et al. 2014), especially in North America and to a lesser extent in Europe (Sundquist et al. 2011; Van Dyck, 2010), but are now also being applied outside of these regions (Oyeyemi et al. 2016). In the transport domain, the focus tends to be on the potential and suitability for a street system to be used for walking (Moudon and Lee, 2003), whilst in the health domain, walkability models are used to assess dose-response relationships between the built environment and physical activity (Van Dyck et al, 2012). Walkability metrics of the built environment are often used as variables in studies which aim to ascertain the health outcomes of living in neighbourhoods with differing geographical and population attributes (Buman et al, 2010).

Walkability can be defined in several different ways (Lo, 2009), and therefore attempts to measure it do not necessarily coincide well with its theoretical or conceptual underpinnings. In the realm of public health studies, the focus is on an area's suitability for walking. Previous research has found that people walk more in neighbourhoods with multiple destinations and where the environment enables more opportunities for walking, with many street junctions as well as good connections to other forms of transport. Such studies also take account of reasons for walking, such as distance to shops and businesses (Frank et al., 2005; GilesCorti et al., 2005; Song 2005; Moudon et al., 2006). Their findings form the basis for a vast array of health studies, which audit neighbourhood walkability based on such parameters, where a neighbourhood's walkability is considered to be a proxy for the levels of physical activity within a population within a specific area. Such walkability frameworks examine a range of variables in order to ascertain which aspects of the environment or socio-cultural make-up correlate most significantly with health outcomes, and then these features are considered to be determinants of walkability.

Walking activity is often subdivided within walkability studies into different domains in order to enable the extraction of the environmental attributes that contribute to different types of walking activity, since different variables are likely to affect each activity type differently (Sallis et al., 2006). The most common subdivision of walking activities is between walking for transport and walking for recreation. Walking for transport includes walking to places of work, visiting shops and other services as part of daily routines. Walking for recreation is walking as a pastime or as part of an exercise routine. This article focuses upon walking for transport, which is classified as a form of active travel or active transport, alongside other modes such as cycling.

The literature on walkability tends to focus on walking as being beneficial to health. However another important aspect is the role of walking as a function of the vitality and liveability of cities. In the transport literature, work by Jones et al (2007) points to the tension that can arise between routes being heavy trafficked by both pedestrians and motorised traffic (with the consequential impact on the pedestrian walking environment), whilst in the urban design literature there is an increasingly large body of work on how well-connected and spatially coherent town centres benefit from increased footfall as well as dwell time (Carmona, 2015; Karimi, 2012). Qualities of the walking environment such as lighting, pavements and street block size have also been found to correspond to higher rates of walking (Forsyth and Southworth, 2008; Frank et al., 2010). 
There is also an argument that areas that are more walkable and where there is a greater level of street-based activity are more likely to become 'creative' hubs due to the type of individuals that will be attracted to work and live there (Florida, 2005). More prosaic analysis focuses on land and property values, demonstrating that walkable areas are more liveable and hence, more desirable when measured by property values (see e.g. Chiaradia and Koch, 2013), whilst recent work in the UK points to the importance of walkability for the longterm viability of smaller town centres (Vaughan et al., 2013).

With the majority of studies looking at the home environment and the levels of walking activity associated with those environments, a consideration of the way the urban system functions as a whole and how it can be adapted to enable the greatest level of physical activity for transport purposes for people making trips outside of their immediate home environment can be lost. The methods presented in this article aims to address some of these limitations, by analysing the city as a single continuously varying and related system, to enable considerations of how the built environment can be adapted, enhanced and targeted for system-wide interventions that work synergistically for the trips within and through any location within the city - considering the city as a single system.

The aspects of the built environment that this paper focuses upon are land use, transport accessibility, street network structure and residential population density. These aspects were chosen both due to their statistically significant associations with walking activity both in walkability and non-walkability focussed literature (Hillier et al., 1993; Hillier, 1996; Frank et al., 2010; Grasser et al., 2013; Giles-Corti et al., 2005; Oakes et al., 2007; Sakar et al., 2015; Heath el al., 2006). Some of the walkability literature accounts for the street system's structure, and potential to influence walking behaviours, by applying street connectivity measures or proxies for street connectivity. Block size is frequently used as a proxy for street connectivity, whereby smaller blocks suggest greater connectivity (Oakes et al., 2007). Another measure of connectivity is the number of true junctions ( 3 or more street segment end points coinciding) per unit area of analysis e.g. block, block grouping or statistical unit area, often called junction density (Grasser et al., 2013). The methods used here differ from this approach, by substituting analysis of connectivity, with measures of the street network as a system, using space syntax methods.

Space syntax is a set of theories and techniques that are centred on understanding the relationships between and society and space. The central theory is that the structure of space is an outcome, and in turn influencer of social structures and interaction. Of principal concern to these theories are the way in which people move, see and interact with others and how the spatial structures of building interiors, settlements and cities that a society develops, inhibit, encourage and structure the potential for patterns of movement and encounter to emerge. This theory is supported by techniques for evaluating street (or building) networks. In contrast with measures of connectivity such as junction density, space syntax analysis is based on graph-based models of space, which are used to investigate the influence of the shape, geometry and configuration of spatial systems on human behaviour (Volchenkov and Blanchard, 2008). The two principal measures used in space syntax analysis are choice and integration, which are expressed in this paper using the commonly known terminology of angular closeness centrality and angular betweenness centrality, respectively. These measures originate in the work of Freeman (1977) looking at social network structure, and were first applied to the study of the social nature of spatial systems by Hillier and colleagues in the 1970s (Hillier and Hanson, 1984).

Space syntax network centrality measures are used in the approach presented here in order to incorporate the aspects of pedestrian demand that are influenced by the spatial structure of urban space. Importantly for walkability applications outside of North America and other areas where urbanisation took place in relatively recent times, the highly complex nonrectilinear grids that occur in cities that have developed over longer time periods create nuances in the street structure that may benefit from methods such as space syntax, that can capture the structural properties of these highly complex irregular street network systems. The space syntax theory of natural movement (Hillier et al., 1993) proposes that a significant proportion of movement through urban streets is principally determined by the relational structure of the street network system, before other factors, such as attractors, come to play. The multiple foci of economic activity and concentrations of street-based 
activity that are seen in all cities have been suggested to be the result of multiple centres operating as an interdependent network of smaller and larger centres.

Empirical research using space syntax methods has found a strong relationship between its graph-based measures of street networks and pedestrian flows (Hillier et al., 1993), bicycle flows, (McCahil and Garrick, 2008) and public transport passenger flows (Law et al., 2012). Space syntax analysis has also been used in studies of healthy built environments, such as the work of Sarkar et al. (2013); Koohsari et al. (2013); Sarkar et al. (2015); Lamíquiz and López-Domínguez, (2015).

The specific methods that are used to construct each of the pedestrian demand model components are described in the following section.

\section{Methods}

The approach that is presented here focuses on four principal built environment characteristics: land use, residential population, public transport accessibility and street network structure as measured using space syntax analysis methods. As well as providing equivalent data to the North American approach to modelling walkability, the advantage of using these characteristics is that they can be constructed from readily available data in the UK (similar datasets can be found worldwide), enabling the application of the methods to many different contexts. Table 1 contains a list of datasets as well as the choice of variables for each characteristic.

\begin{tabular}{l|c|c|c|c}
\multicolumn{1}{c|}{ Datasets } & \multicolumn{3}{c}{ Variables } \\
\cline { 2 - 5 } & Land Use & Transport & $\begin{array}{c}\text { Street } \\
\text { Network }\end{array}$ & $\begin{array}{c}\text { Residential } \\
\text { Density }\end{array}$ \\
\hline $\begin{array}{l}\text { Ordnance Survey MasterMap } \\
\text { Topography } \\
\text { Building footprints }\end{array}$ & $\bullet$ & & & \\
\hline $\begin{array}{l}\text { Ordnance Survey AddressBase } \\
\text { Premium }\end{array}$ & & & \\
$\begin{array}{l}\text { Address location and land use } \\
\text { classification }\end{array}$ & $\bullet$ & & & \\
\hline $\begin{array}{l}\text { Ordnance Survey Meridian 2 } \\
\text { Street network }\end{array}$ & & & & \\
\hline $\begin{array}{l}\text { Ordnance Survey Building Heights } \\
\text { Database } \\
\text { Building heights }\end{array}$ & & & & \\
\hline $\begin{array}{l}\text { Department for Transport NaPTAN } \\
\text { Database }\end{array}$ & & & & \\
Rail, metro, bus and tram stop locations & & & & \\
\hline $\begin{array}{l}\text { UK Census } \\
\text { Population Density }\end{array}$ & & & & \\
\hline
\end{tabular}

Table 1 Datasets used for constructing corresponding built environment variables

The process of constructing the built environment variables is as follows: once each variable is constructed from the datasets in table 1 a geographic data surface, or raster, is generated by interpolation (see Equation 1), with the exception of the transport accessibility variables that use interpolation to generate the accessibility values themselves. The interpolation is carried out to produce cell sizes of $25 \mathrm{~m}^{2}$ for the whole of London. Rather than assigning pedestrian demand values to discrete areas, such as census areas, rasters are used instead (a raster is a matrix of cells representing data across an area). This allows the model to capture the constantly varying qualities of urban space as perceived by people as they walk the city streets, creating a more accurate representation of environmental perception, which is continuous rather than discrete. Furthermore it enables interoperability across a wide range of other datasets so that it can be used for analysis against as many other data sources as required, such as socio-economic indicators, traffic levels, greenness, pollution 
and so on. Since the surface cells are $25 \mathrm{~m}^{2}$ in size this also allows for micro-scale evaluations at the street and street section level for localised analysis. The next stage is for the values to be normalised by $z$ scoring (see Equation 2). Finally the values within each variable raster are re-scaled between 0 and 1 so that they can be directly compared to one another in the statistical testing phase.

$$
Z\left(S_{0}\right)=\sum_{i=1}^{N} \lambda_{i} Z\left(S_{i}\right)
$$

Where;

$Z\left(S_{i}\right)$ is the measured value at the ith location

$\lambda_{i}$ is the distance weight

$S_{0}$ is the prediction location

$N$ is the number of measured values

Where;

$$
z=\frac{x-\mu}{\sigma}
$$

$z$ is the $z$-score

$x$ is the individual variable value

$\mu$ is the mean of variable population

$\sigma$ is the standard deviation of population

In order to evaluate the effectiveness of the built environment variables at estimating the location and intensity of pedestrian activity across London, a dataset that represents actual measured pedestrian activity was used. The pedestrian activity dataset was provided by Transport for London (TfL). It was extracted from the London Travel Demand Survey (LTDS) carried out by TfL. Each year 8,000 randomly selected households complete travel diaries. The dataset used here is based on six years of data from which all walking trips stages were extracted, equating to 300,000 trips across the London for a six-year period. The random selection process and length of data collection make this data a representative sample of the population as a whole.

The origins and destinations of every walking stage were then geo-located, and route between origin and destinations generated. These data were then processed to calculate the intensity of pedestrian activity, measured in metres travelled per square metre within a given area. The areal unit used to aggregate the pedestrian trip stages are hexagons with a diameter of $350 \mathrm{~m}$. This equates to 15,477 hexagons with pedestrian activity values across the Greater London area, with the measurement given as metres walked per square metre within each hexagon. This equates to a measure of the intensity of pedestrian activity in a given location and is used here as the pedestrian demand variable. In order to compare the built environment variables to the pedestrian activity data they were aggregated up from the $25 \mathrm{~m}^{2}$ raster resolution to the $350 \mathrm{~m}$ diameter hexagons by summation of the values of the raster cells that fall within each hexagon (Figure 1). This process was applied to each built environment variable. This same principle can be used across a variety of other datasets for other analytical purposes as suggested earlier, such as statistical geography boundaries for socio-economic analysis, or road areas to examine relationships to traffic flow and community severance. 


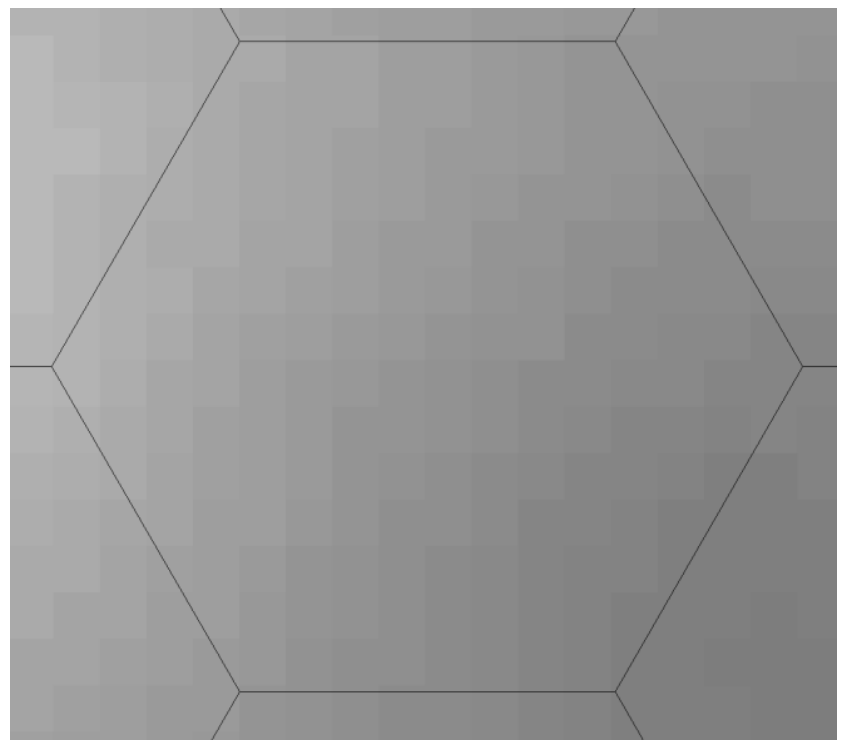

Figure $1350 \mathrm{~m}$ diameter hexagons used to aggregate pedestrian activity data overlaid on $25 \mathrm{~m} 2$ resolution built environment variable raster

The pedestrian activity data is used here to evaluate the built environment variables' relationship to pedestrian demand, and is then used to calibrate their relative weighting in order to generate the pedestrian demand model. (Demographic information in the London Travel Demand Survey could be used for other types of analysis, but that is beyond the scope of this study). The area that the built environment variables were calculated for is shown in Figure 2. This corresponds to the Greater London area.

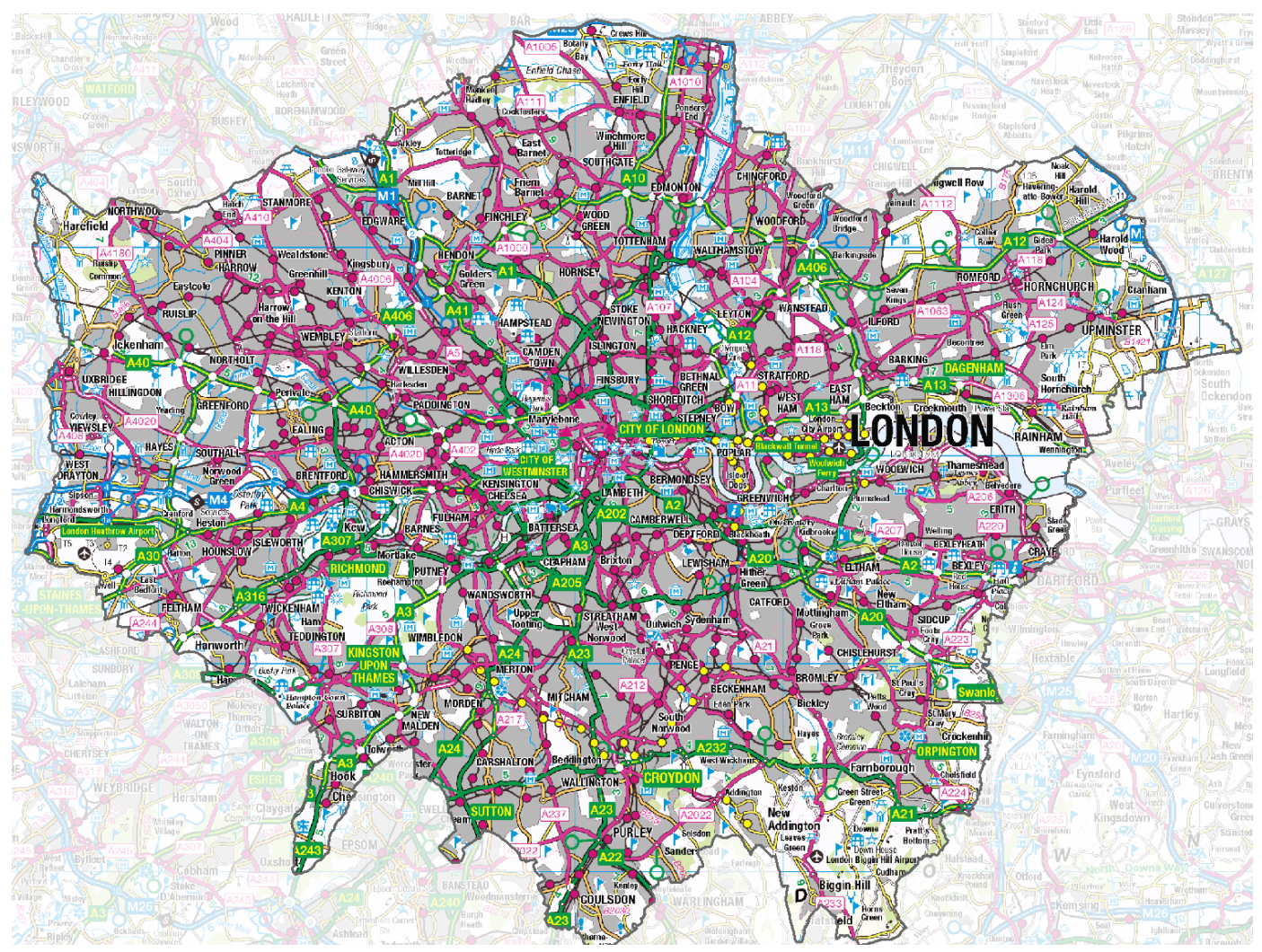

Figure 2 Map showing the area within Greater London area covered by the built environment variables and subsequent pedestrian demand model. Contains Ordnance Survey data @ Crown copyright and database right 2016. 


\subsection{Land Use Diversity and Intensity}

Land use and its relationship to travel behaviour and transport infrastructure has been studied extensively in Land Use Transport Interaction (LUTI) modelling (Wegener, 2014; Wegener and Fürst, 2004), and detailed characteristics of land use in urban areas have been found to affect mode choice and trip rates (Cervero and Kockleman, 1997), whilst physical activity has been shown to be influenced by land use (Heath el al., 2006). Land use diversity is a measure of the degree to which there is a mix of a given set of categorised land uses within a pre-defined area. Land use mix can be characterised in numerous way but a commonly used approach in walkability studies as well as other urban research domains is to use an entropy based measure of diversity, Shannon's Diversity Index (which measures the abundance of land use types present within an area) is used as a basis of a second calculation, which accounts for the evenness of the distribution of land use classes, Shannon's Equitability (Frank et al. 2010, Van Holle, et al. 2012). This intends to capture the diversity and composition of land uses within a given unit area. An area that has all land use classes present and in equal proportion, would score a value of 1 , whilst an area with only one land use present would score 0 . The following shows the equations for the two indices.

Shannon's Diversity Index $(\mathrm{H})$ :

$$
H=-\sum_{i=1}^{s} p_{i} \ln p_{i}
$$

Where;

$H$ is Shannon's Diversity Index

$i$ is the proportion of one land use area of all land uses present

$p_{i}$ is the total value of land use area

This equation assesses the diversity in terms of the proportion of a particular land use $(i)$ relative to the total number of land uses $\left(p_{i}\right)$ in a given area. It does not account for the equitability of the mix of different land uses that are present. To incorporate this into the land use diversity index component, Shannon's Equitability $\left(E_{H}\right)$ is then calculated on the $\mathrm{H}$ value from the first equation. Equation 4 denotes Shannon's Equitability.

Where;

$$
E_{H}=\frac{H}{H_{\max }}=H / \ln S
$$

$E_{H}$ is the Shannon's Equitability Index

$H$ is the Shannon's Diversity Index value

$S$ is the number of data classification categories

In this instance of calculating land use diversity the block is used as the spatial unit for attribution of land use diversity values. The block is defined as any continuous area bounded by roads or other barriers on all sides that have no roads passing completely through it. The land uses that are attributed to each block capture all land uses that occur at the addresses located within the block. In this case land use diversity and equitability is calculated across three dimensions, incorporating a volumetric value for each address based on footprint and height of each building, and all land uses on all floors of the building. The land use classification schema used is made up of 11 categories: commercial industrial, commercial non-industrial, commercial general, commercial agricultural, retail, food retail, food and drink, tourism and leisure, community and health, transport, residential and education.

The second stage of calculating the intensity and diversity is to multiply the equitability value calculated from the composition and diversity of the three-dimensional land uses within a block by the intensity of land use. Intensity here is defined as the cubic metres of building per square metre of land area of a given block; this can be thought of as a variation on the common floor area ratio (FAR), but using total volume rather than total floor space, therefore described as volume area ratio (VAR). Building volumes have been used primarily to estimate building energy consumption for heating (Catalina et al. 2008; Ourghi et al. 2007). In the absence of city-wide land use classification by floor area the combination of height and address data can be used to estimate the volume of each address within each building, and therefore the volume per land use classification of each address. 
The combination of diversity equitability and intensity accounts for the vastly differing utilisation of land across the city, and differentiates between locations that might have similar land use diversity but differing land utilisation intensities. The resulting metric captures both diversity and intensity of land use as multiplying factors of the potential for these attributes of the built environment to generate pedestrian activity. Using these methods three land use metrics were generated and tested against the pedestrian demand data: land use diversity equitability, land use intensity and intensity of land use diversity equitability.

\subsection{Public Transport Accessibility}

Public transport, whilst not available uniformly in urban areas and in some cases not available at all, is in the case of London central to population mobility, with 44 per cent of daily trips stage being made using public transport (TfL, 2016). It was therefore essential to include it as a variable. In order to do this every bus stop, tram stop, railway station and London Underground station within London were located. The locations were then used to generate accessibility surfaces for bus stops and tram stops (radius $500 \mathrm{~m}$ ), and London Underground and rail stations (radius $1,000 \mathrm{~m}$ ), a 6-minute and 12-minute walk, respectively. These variables were generated using interpolation (see Equation 1). The $500 \mathrm{~m}$ and $1000 \mathrm{~m}$ search radii were used, so that up to the search radius the value declines linearly from one to zero. In locations where access points coincide within the search radii the value where they overlap results in addition of the values at a given location. This process was carried out for the two types of transport access location (bus and tube/rail); they were then combined together to generate as a combined transport accessibility variable that included all modes. The three different transport accessibility variables that were individually evaluated against the LTDS pedestrian density data.

\subsection{Residential Density}

Residential density is calculated as two different variables: first, the number of individual residential addresses per block area and second, residential population density. The area that can be used to define the address density can either be the block that the residential units are situated within aggregated blocks or another areal unit, but is typically defined as the number of residential units as a ratio of the total land area within a block (Frank and Pivo, 1994; Frank et al., 2010; Leslie at al., 2005). The residential population density can be associated with any UK statistical geography, in this case Census Output Areas are used, the smallest UK census geography with approximately 25,000 in London. The residential population density is calculated as the number of residents per area of the Output Areas. Residential address density is tested alongside population density to ascertain if it will correspond to levels of pedestrian activity, given that it corresponds more closely to the actual location of dwellings and potentially captures the likely intensity of trips generated by individual dwellings. Residential address density is calculated using the same block areas as used in the land use diversity and intensity calculations. All the residential addresses were extracted and counted for each block area. The number of addresses in a block is divided by the block's area to generate a density value of addresses per square metre.

\subsection{Space Syntax Street Network Centrality}

This approach incorporates space syntax methods to evaluate the spatial structure of the street network; these are a set of graph-based parameters that measure the closeness and betweenness centrality of spatial networks. The methods have three defining analytical features in comparison to other network analysis approaches: first, the street segment itself is the urban unit rather than the points of connection between street spaces; this is referred to as the dual graph representation. This stems from a desire to approximate people's actual experience of moving through the urban environment from space to space rather than from intersection to intersection. Second, the way that distance is measured in the street network using space syntax techniques is not metric, but is done by calculating the angular change 
when moving from one street segment to another. For example, closeness centrality for a given street segment will be higher if angular change is minimized between it and all other street segments in a given network, whilst it will have low closeness centrality if many large angular changes are required to access all other street segments in a given network. In contrast, betweenness centrality accounts for the centrality of a street segment on routes between any two street segments. A street segment will have a higher betweenness centrality if it is traversed many times on the shortest angular path between a pair of origins and destinations. Third, when the analysis is carried out a (metric) search radius can be specified within which to calculate the centrality values. This allows the analysis to examine local (e.g. $400 \mathrm{~m}$ search radius) centrality, as well as regional centrality (e.g. 10,000m search radius) - or any other radius required. In this context identifying the search radius that corresponds most closely to pedestrian activity levels is important to understand the structuring of pedestrian behaviour in relation to distance and therefore the time cost for concentrations of activity. Identifying the principal spatio-temporal distribution of pedestrian activity would have useful applications for both planning and policy.

Angular closeness centrality (Equation 5) measures the reciprocal of the sum of the shortest path between every origin (i) to every destination (k), i.e. the potential of movement to a street segment, due to its angular proximity to all other segments within a specified search radius (Freeman, 1977; Hillier and lida, 2005).

Where;

$$
C_{c}\left(P_{i}\right)=\left(\sum_{k} d_{i k}\right)^{-1}
$$

$C_{c}$ is the closeness centrality

$P_{i}$ is the street segment

$d_{i k}$ is the angular shortest path from $i$ to all destinations $k$

Angular betweenness centrality (Equation 6) measures how many times paths overlap between all pairs of origins (j) and destinations (k), i.e. the potential of moving through a street segment, due to its falling on the shortest angular path between all other segments within a specified search radius (Freeman, 1977; Hillier and lida, 2005).

Where;

$$
C_{B}\left(P_{i}\right)=\sum_{j} \sum_{k} g_{j k}\left(p_{i}\right) / g_{j k}(j>k)
$$

$C_{B}$ is the betweenness centrality

$P_{i}$ is the street segment

$g_{j k}$ is the angular shortest path between all origins $j$ and destinations $k$

The street network that is used for the basis of this analysis is from the UK national mapping agency: Ordnance Survey, Meridian 2 dataset, which provides a high level of detail on pedestrian as well as motorised transport routes. This is processed in the Depthmap space syntax software package (Turner, 2001) to generate centrality values for each street segment. Closeness and betweenness centrality values were generated for a range of search radii in order to identify the search radius that had the best fit to the pedestrian density data. The centrality measure with the search radius that most closely corresponded to the pedestrian density data was then tested against the junction density measure to ascertain the differences between the space syntax method and the junction density method of calculating street accessibility (see section 4).

\section{Statistical testing and results}

Prior to assessing the relationship of the built environment variables to the pedestrian demand dataset, the optimum street network centrality variable was identified, and then subsequently tested against the junction density measure to ascertain any improvement in performance (in predicting pedestrian activity). A range of different search radii (in increments from $400 \mathrm{~m}$ to the maximum of $3000 \mathrm{~m}$ ) for both betweenness and closeness centrality were tested against the pedestrian density data: angular closeness centrality with a 
search radius of $2000 \mathrm{~m}$ was found to have the highest coefficient of determination $(0.76$, $\mathrm{p}<0.001$ ). The coefficient was found to increase incrementally from $400 \mathrm{~m}$ up to $2000 \mathrm{~m}$ and then decline again at larger search radii, though it should be noted that these are small variations (e.g. $1600 \mathrm{~m}=0.75,2500 \mathrm{~m}=0.75$, both $\mathrm{p}<0.001$ ). The betweenness centrality measures did not score as highly, with a maximum of $0.72(p<0.001)$ at a $2000 \mathrm{~m}$ search radius.

The measure of junction density was calculated as the number of junctions of three or more street segment end points per square metre, within each pedestrian density hexagon measurement area. The junction density measure had a coefficient of determination of 0.66 , $\mathrm{p}<0.001$ in relation to the pedestrian density data. Having demonstrated that the space syntax measure of angular closeness centrality $2000 \mathrm{~m}$ was a better predictor of pedestrian densities than junction density and the best performing street network centrality measure it was included in final regression evaluation. The performance of all nine built environment variables as described in section 3 was assessed, as shown in Table 2.

\begin{tabular}{|c|c|c|c|c|c|c|c|c|}
\hline & \multirow[t]{2}{*}{ Variable } & \multirow[t]{2}{*}{ Min. } & \multirow[t]{2}{*}{ Max. } & \multirow[t]{2}{*}{ Mean } & \multirow[t]{2}{*}{ Median } & \multirow[t]{2}{*}{ Std. Dev. } & \multicolumn{2}{|c|}{ Skewness } \\
\hline & & & & & & & Statistic & Std. Error \\
\hline Dependent & $\begin{array}{l}\text { Pedestrian } \\
\text { Density Log } \\
\text { Transformed }\end{array}$ & 0 & 328.61 & 7.35 & 3.87 & 15.52 & 9.04 & 0.02 \\
\hline \multirow[t]{3}{*}{ Land use } & $\begin{array}{l}\text { Diversity } \\
\text { Equitability } \\
\text { Intensity }\end{array}$ & 0 & 141.39 & 6.36 & 4.08 & 8.35 & 5.69 & 0.02 \\
\hline & $\begin{array}{l}\text { Diversity } \\
\text { Equitability }\end{array}$ & 0 & 141.68 & 27.51 & 23.21 & 19.29 & 1.17 & 0.02 \\
\hline & Intensity & 0 & 123.54 & 3.56 & 2.09 & 4.98 & 5.84 & 0.02 \\
\hline \multirow[t]{2}{*}{$\begin{array}{l}\text { Residential } \\
\text { Density }\end{array}$} & $\begin{array}{l}\text { Population } \\
\text { Density }\end{array}$ & 0 & 126.2 & 6.11 & 4.96 & 4.47 & 3.73 & 0.02 \\
\hline & $\begin{array}{l}\text { Address } \\
\text { Density }\end{array}$ & 0 & 157.72 & 10.95 & 8.79 & 8.27 & 3.87 & 0.02 \\
\hline $\begin{array}{c}\text { Street } \\
\text { Network }\end{array}$ & $\begin{array}{c}\text { Closeness } \\
\text { Centrality } \\
2000 \mathrm{~m}\end{array}$ & 0 & 156.73 & 29.13 & 26.28 & 19.85 & 1.4 & 0.02 \\
\hline \multirow[t]{3}{*}{ Transport } & $\begin{array}{c}\text { Combined } \\
\text { Bus, Rail and } \\
\text { Metro } \\
\text { Accessibility }\end{array}$ & 0 & 161.65 & 17.05 & 13.76 & 15.97 & 1.88 & 0.02 \\
\hline & $\begin{array}{c}\text { Bus } \\
\text { Accessibility }\end{array}$ & 0 & 136.14 & 18.72 & 16.93 & 15.55 & 1.13 & 0.12 \\
\hline & $\begin{array}{l}\text { Rail and Metro } \\
\text { Accessibility }\end{array}$ & 0 & 163.4 & 9.87 & 2.58 & 15.27 & 2.8 & 0.12 \\
\hline
\end{tabular}

Table 2 Variables and descriptive measurements $(\mathrm{N}=15,085)$

Table 2 shows all nine built environment variables that were to be evaluated, and their respective central tendency, variability and distribution characteristics. In total 15,085 data points were used for the subsequent data modelling. The distribution of values for the dependent variable deviates from symmetry around the mean with positive skewness indicative of a greater number of smaller values present in the dataset and a small number of very high values. When the pedestrian density variable is plotted geographically it can be seen that the majority of the pedestrian density high-activity zones are clustered around the 
London Central Activity Zone and along the main arterial routes (Figure 3). This distribution of pedestrian activity is not surprising, as quantitative geographic research has previously demonstrated that many human attributes display moderate positive spatial autocorrelation (Schelling, 1969). Taking this into account, when the pedestrian activity was examined using the Moran's I measure of spatial autocorrelation (Anselin, 1995; 2005), two types of local spatial distributions were identified as significant (based on 999 permutations and $p<.001$, see Figure 4): first where high values were clustered in close proximity to other high values, i.e. zones of high pedestrian activity; and second, where low values were clustered near other low values, i.e. zones of low pedestrian activity. Note that Figure 4 also illustrates that there are a number of spatial outliers, where high values are clustered near low values and vice versa. 


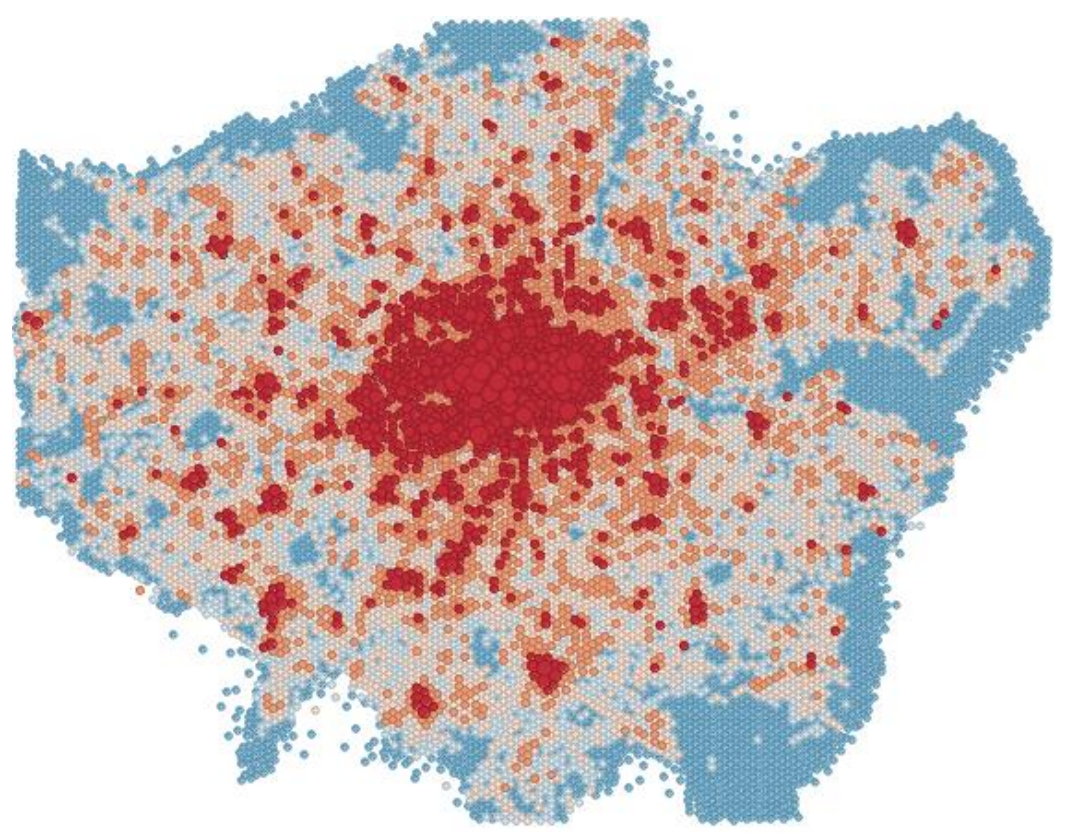

Hinge=1.5: pdensity_2

$\square$ Lower outlier (0) [-inf : -9.44] $<25 \%(3773)[-9.44: 1.03]$ $25 \%-50 \%(3772)[1.03: 3.87]$ $50 \%-75 \%(3773)[3.87: 8.01]$ $>75 \%(2661)[8.01: 18.5]$

Upper outlier (1112) [18.5: inf]

Figure 3 Pedestrian density in London

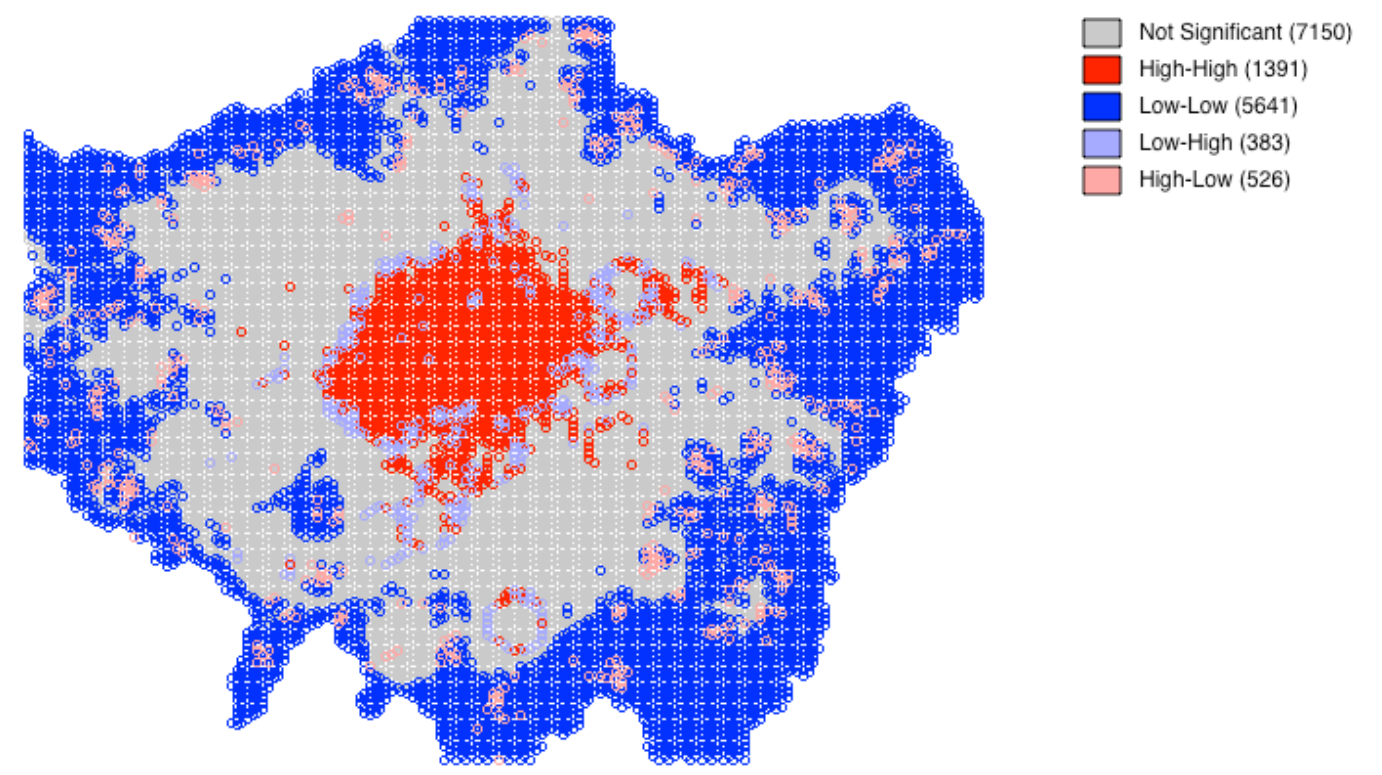

Figure 4 Calculation of Moran's $I$, illustrating the incidence of significant local spatial autocorrelation. Locations are colour coded by type of spatial autocorrelation (e.g. high-high are high values close to other high values)

Based on these findings, a spatial weights matrix was calculated to account for local spatial variability when evaluating the pedestrian activity against the set of independent variables. The relationship between neighbouring areas was captured using an adjacency matrix of up to two neighbours away, using Queen Contiguity (namely computing distance between adjacent neighbours), corresponding to 800 -meter distance. The local spatial interaction is defined as follows (Equation 7):

$$
W_{i j}=\frac{C_{i j}}{\sum_{j=1}^{N} C i j}
$$


Where; $C_{i j}=1$ when $i$ is linked to $j, C_{i j}=0$ when otherwise.

Regression modelling was used to examine the relationship between pedestrian activity and the independent variables (Equation 8). This is defined as:

Where;

$$
Y=\beta_{0}+\beta_{1} X_{1}+\beta_{2} X_{2}+\cdots+\beta_{n} X_{n}+W_{y}+\varepsilon
$$

$Y$ is the dependent variable;

$\beta_{0}$ is the constant;

$\beta_{1 \ldots n}$ is the coefficient for the independent variable $X_{1 \ldots n}$;

$W_{y}$ is the spatial weight matrix for the dependent variable;

$\varepsilon$ is the error term associated with the dependent variable that cannot be explained by the independent

variables $X_{1} \ldots n$.

Next, an evaluation of nine independent variables was performed; where individual relationships between the depended and independent variables were modelled using individual Poisson regressions. First the pedestrian density dataset was randomly split into two parts 60:40 for this training and testing purpose (see Figure 5). Using this approach 60\% of the data $(9,051$ cases) were used to conduct a Poisson regression analysis and obtain the coefficient(s) for the independent variables (see Figure 6). These coefficients then were used to evaluate the remaining $40 \%$ of the data $(6,034$ cases). In order to determine how well the model performed in predicting the remaining $40 \%$ of unknown values, the mean absolute error and coefficient of determination were used as evaluation parameters. The smaller the mean absolute error, which is the average of all the distances of the predicted values, from the true values, the better the model performance. The coefficient of determination $(R 2)$ specifies how well the model accounted for the variability in the data, i.e. it summarizes the explanatory power of the regression mode, where the value closer to 1 is indicative of a good model fit.

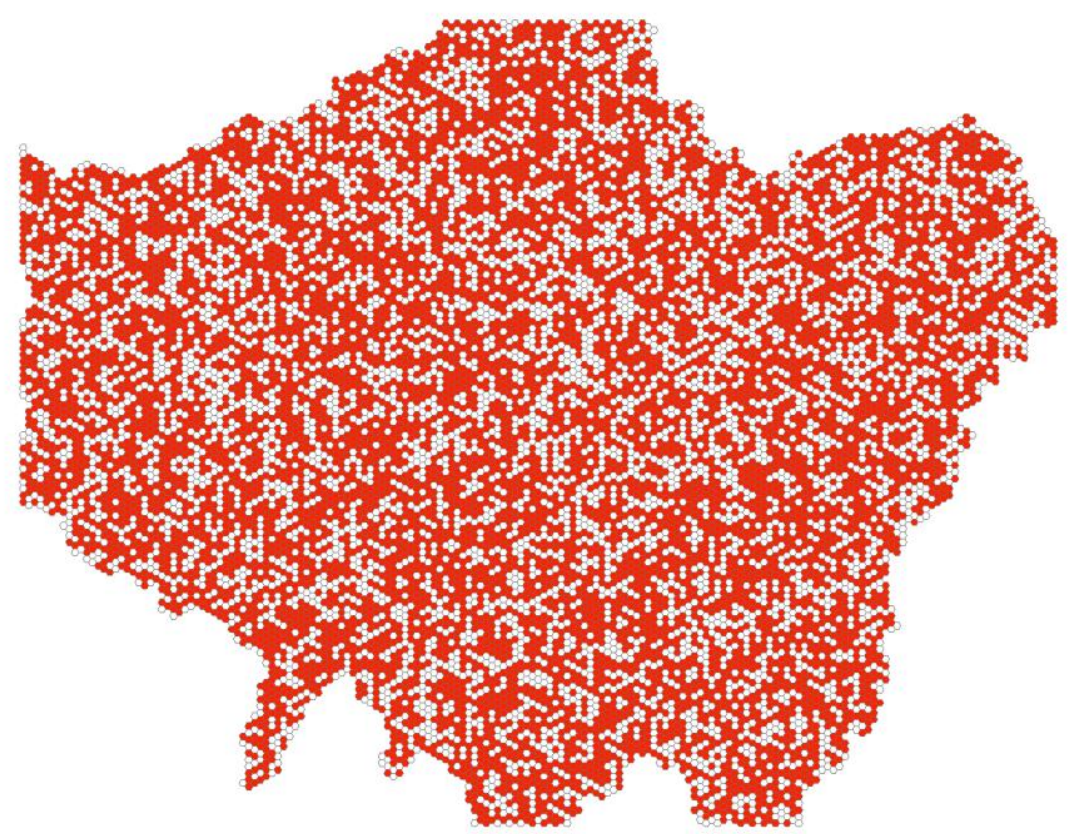

Figure 5 60\% of randomly selected cases across the dataset (9,051 hexagons coloured in red) 


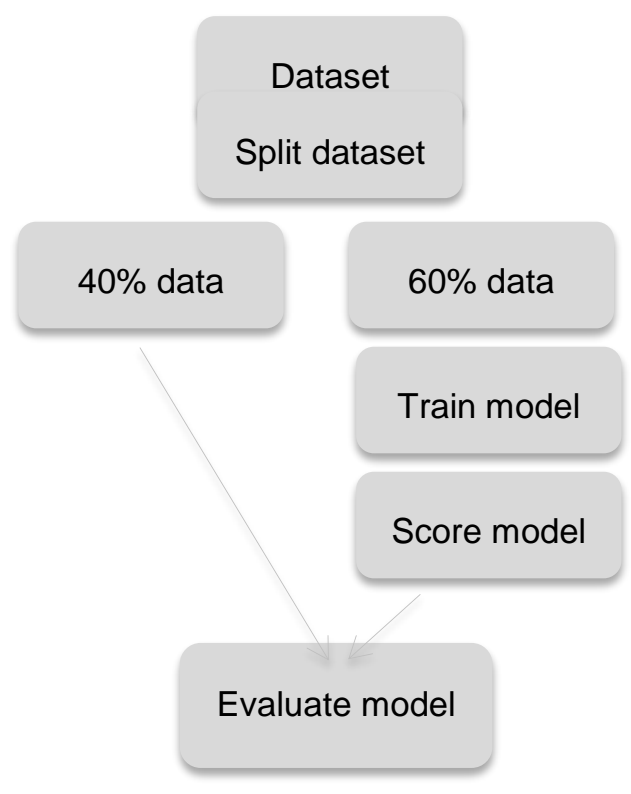

Figure 6 Schematic representation of the data testing and evaluation process

Table 3 lists the evaluation parameters for each independent variable It can be seen that of the three different ways accounting for the land use variables, the combined diversity equitability and intensity performed the best in terms of fit, and had smallest error. Similarly, the population density variable performed better than the residential address density variable, and the combined variable for rail and bus outperformed bus or rail as standalone variables. Based on these evaluation criteria the best variables out of nine from each category were selected to be included in the final regression, which are:

- $\quad$ Land use diversity equitability intensity

- Population density

- Closeness centrality search radius $2000 m$

- Combined bus, rail and metro accessibility 


\begin{tabular}{|c|c|c|c|}
\hline & Variable & $\begin{array}{c}\text { Mean Absolute } \\
\text { Error }\end{array}$ & $\begin{array}{l}\text { Coefficient of } \\
\text { Determination }\end{array}$ \\
\hline \multirow[t]{3}{*}{ Land use } & $\begin{array}{l}\text { Diversity } \\
\text { Equitability } \\
\text { Intensity }\end{array}$ & 2.88 & 0.82 \\
\hline & $\begin{array}{l}\text { Diversity } \\
\text { Equitability }\end{array}$ & 3.77 & 0.64 \\
\hline & Intensity & 3.08 & 0.73 \\
\hline \multirow[t]{2}{*}{$\begin{array}{l}\text { Residential } \\
\text { Density }\end{array}$} & $\begin{array}{l}\text { Population } \\
\text { Density }\end{array}$ & 3.36 & 0.62 \\
\hline & Address Density & 3.43 & 0.60 \\
\hline Street Network & $\begin{array}{c}\text { Closeness } \\
\text { Centrality 2000m }\end{array}$ & 2.82 & 0.76 \\
\hline \multirow[t]{3}{*}{ Transport } & $\begin{array}{l}\text { Combined Bus, } \\
\text { Rail and Metro } \\
\text { Accessibility }\end{array}$ & 2.73 & 0.80 \\
\hline & Bus Accessibility & 3.14 & 0.74 \\
\hline & $\begin{array}{l}\text { Rail and Metro } \\
\text { Accessibility }\end{array}$ & 3.50 & 0.72 \\
\hline
\end{tabular}

Table 3 Evaluation of Poisson regression results from 11 independent variables $(N=9,051)$

Prior to running the final regression model, all four variables were tested for multicollinearity in order to determine the degree of similarity of the independent variables, and whether or not they account for the same variance in the data. The similarity of the variables will correspond to a strong correlation and in the regression model will make the estimates of the coefficients unstable, causing the standard errors of the coefficients to be inflated. Table 4 shows that VIF values for these variables is between 1 and 10, which is indicative of there being no multicollinearity, and the tolerance values indicate that for example $56 \%$ of variation in combined transport accessibility variable cannot be accounted for by the other three variables. Hence, all four variables were included within the same regression model.

\begin{tabular}{l|cc}
\multicolumn{1}{c|}{ Variable } & Tolerance & VIF \\
\hline Diversity Equitability Intensity & 0.46 & 2.16 \\
Population Density & 0.38 & 2.61 \\
Closeness Centrality 2000m & 0.52 & 1.87 \\
Combined Bus, Rail and Metro Accessibility & 0.56 & 1.77
\end{tabular}

Table 4 Collinearity statistics

Table 5 shows the weighting obtained from the Poisson regression model against the $40 \%$ remaining data. The coefficient of determination shows that $92 \%$ of the total variation in the pedestrian density data is explained by the linear relationship between four independent variables and depend variable. This model is the closest in its predictions to the true values, since the mean absolute error indicates that the absolute difference between true values and predicted values is smaller than in the previous regression models shown in Table 3. Using the weights from the regression model the values of pedestrian demand for London can be generated. The combination of the four weighted variables is shown in Figure 7, as a 3D pedestrian demand surface for the London study area. 


\begin{tabular}{l|l} 
Mean Absolute Error & 1.60 \\
Coefficient of Determination & 0.92 \\
& Weight \\
\hline Bias & -4.95 \\
Diversity Equitability Intensity & 0.82 \\
Population Density & 0.57 \\
Closeness Centrality 2000m & 2.30 \\
Combined Bus, Rail and Metro & 2.89 \\
Accessibility & \\
Local spatial autocorrelation & 0.14
\end{tabular}

Table 5 Evaluation and weight estimation from the Poisson regression model

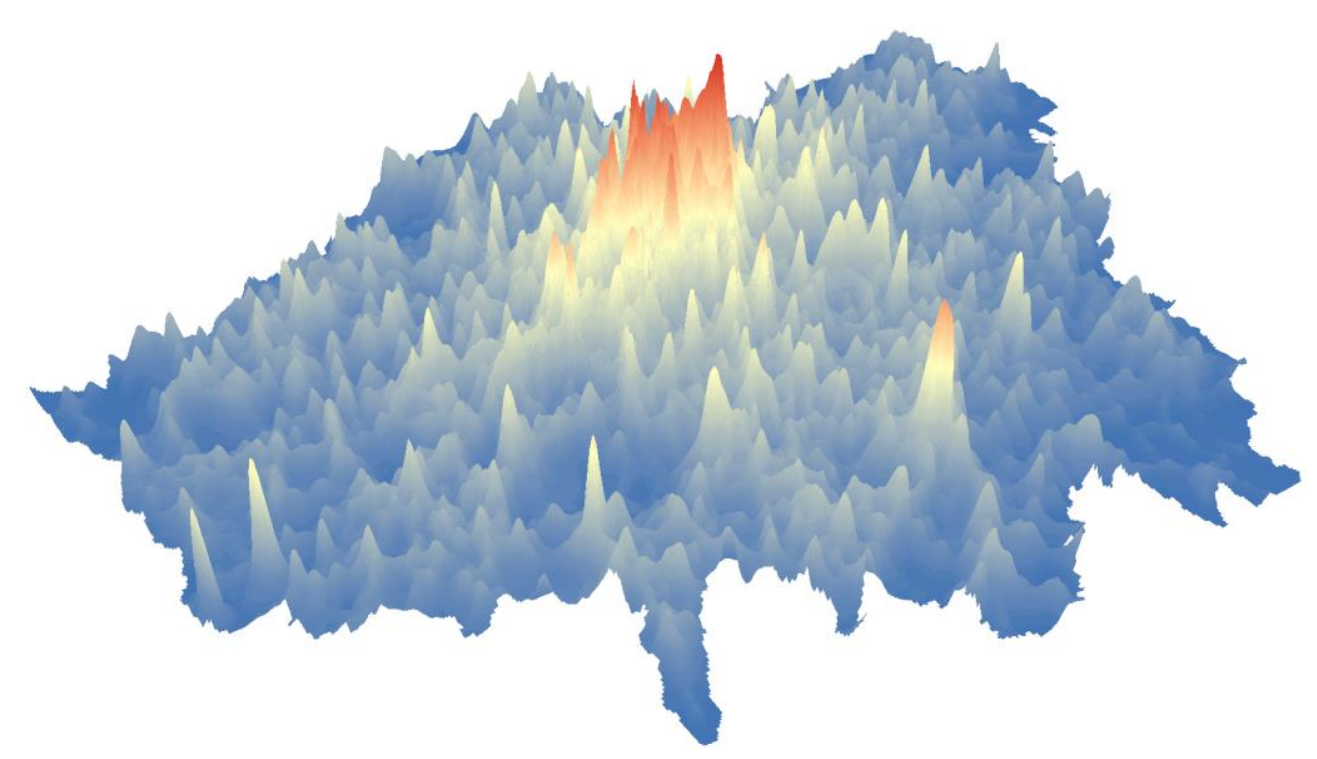

Figure 7 Weighted combination of final four built environment variables, coloured in a range from red (high pedestrian demand) to blue (low pedestrian demand). Height indicates the magnitude of the pedestrian demand value.

\section{Discussion}

The analysis of the built environment variables and the London Travel Demand Survey pedestrian density data demonstrates the strength of using spatially detailed variables and space syntax methods to construct a model to predict the likely intensity and location of pedestrian activity. This is demonstrated by the significant and positive associations between the built environment variables and the measured pedestrian density, as well as the performance of the weighted model at predicting pedestrian density at locations with excluded data, based on a random sample. Specific transport accessibility, street network centrality and land use diversity variables were shown to be the most important factors, as shown by their coefficients of determination. This suggests that the structuring of locations of intensity of pedestrian activity within the city is largely dependent on the accessibility and attractiveness of a location within the broader context of the city, influenced by public transport, land use diversity and intensity and the street network structure. The caveat to this being that it has only been demonstrated in London so further studies in other contexts 
would be necessary to determine whether the identified relationships vary between geographical contexts.

Whilst residential population density was shown to have a significant relationship to the intensity of pedestrian activity, it did not demonstrate such high levels of determination as the other factors. This strengthens the argument for constructing a model that takes account of spatial configuration, rather than within census tracts. Nonetheless, higher levels of residential density can be said to contribute positively to levels of pedestrian activity.

The optimal weights that were calculated show that the transport accessibility and closeness centrality search radius $2000 \mathrm{~m}$ variables have the most significant weights in the final model of pedestrian demand, whilst land use diversity equitability intensity and population density have smaller weightings. The combined and weighted model accounts for $92 \%$ of the variation in pedestrian demand and can therefore potentially serve well as an active transport evaluation, planning and design tool due to its demonstrated ability in predicting pedestrian demand. The weightings suggest it may even be possible to develop pedestrian demand models solely based on transport accessibility and street network centrality. The weights of the built environment variables in the model would need to be tested in other locations to ascertain if they remain similar or vary between different urban settings.

The analysis also demonstrated that the space syntax based centrality measure corresponds to pedestrian activity to a greater degree than junction density. This is important for walkability and pedestrian demand modelling since this method of street network analysis could be incorporated into walkability and pedestrian demand studies more widely to improve their performance. This will especially be true for modelling walking for transport, given that active transport walking is more likely to follow the spatial structure of the street network than walking for leisure. The analysis also highlights the importance of the spatial geometry of cities in shaping pedestrian behaviour, something that is not captured with junction density or simple connectivity measures, which take no account of the morphology of the built environment. Testing this methodological approach in the context of orthogonal grid systems, such as those found in the majority of North American cities would be important to see if this applies outside of the organic (rather than planned) street network system found in London, and other older urban street network systems.

During the built environment variable assessment phase variations of each variable were tested to choose the best performing variables to include in the modelling phase. The evaluation of the land use variables showed that the combined measure of diversity equitability and intensity was the best predictor of pedestrian demand. Land use diversity equitability on its own was the worst of the three, with intensity expressed as building volume area ratio at the block level outperforming it. This finding could be useful for locations where detailed land use information is not available, but building heights and footprints are, so that land use intensity as expressed volumetrically could be used for predicting pedestrian demand.

The finding that angular closeness centrality with a search radius of $2000 \mathrm{~m}$ corresponds most closely to the locations of peak pedestrian density is significant for both theoretical and practical reasons. $2000 \mathrm{~m}$ correspond to approximately a 25 -minute walk, therefore equating to a round trip of 50 minutes. This is close to the theory of travel time behaviour proposed by Cesare Marchetti (1994) of an hour being the amount of time that is spent on average for daily commuting. Given that centres of pedestrian activity across London occur in locations that are accessible for pedestrian round trips of close to an hour, and given that the pedestrian hour of travel-time can be observed in the spatial distribution of pedestrian activity in London, it is suggested this spatial distribution of aggregate pedestrian behaviour could possibly be an organising principle in the way in which concentrations of activity have been distributed across the city over time.

Transport accessibility was found to have the strongest correspondence to levels of pedestrian activity, with the combined measure the best performing. However, it is important to point out the possible circular causality of public transport accessibility and pedestrian activity, as public transport may concentrate in areas where there is greater demand, or demand may increase where public transport is increased. The directionality of the causality will likely vary in different locations but one is not necessarily a predictor of the other, rather they are crucially interlinked. This highlights the paramount importance of public transport to 
all aspects of city processes that rely on pedestrian activity and accessibility. This is linked to another significant aspect of public transport provision and accessibility; that it is generally managed and implemented by a single city-level body, or a small group of service providers. The relevant transport authority will therefore have to take decisions between competing demands of investing in areas where there is proven demand and economic incentive, and investing in areas where there is not a proven case already, but is instead based on forecasts of the likely outcomes of improving transport accessibility in a local area. By using modelling tools such as the one described in this paper the case for that investment might be improved, given that it can be used to assess the impact of changes to transport accessibility on pedestrian activity. This modelling framework also has the potential to contribute to economic models and health impact assessments for local areas. Circular causality is also relevant to land use diversity and intensity, which may generate or result from pedestrian activity. How land use diversity is promoted through planning frameworks and strategies is another important element for understanding the structuring of pedestrian demand.

\section{Conclusions}

The method presented here of generating built environment variables and subsequent modelling of their relationship to pedestrian demand has been demonstrated to be a reliable approach in London, which could augment the current approach to walkability modelling by allowing a detailed, yet city-wide perspective on pedestrian demand and potential. This could enable greater understanding of how to locate and connect active transport infrastructure across the city, increasing the positive impact and decreasing the uncertainty and risk associated with interventions. The space syntax based methods for assessing street network properties hold the potential for improving both walkability studies and associated health research, through more accurate modelling of walkability and pedestrian demand.

The correspondence between the space syntax measure of angular closeness centrality search radius $2000 \mathrm{~m}$ and aggregate spatial distribution of intensity of pedestrian activity indicates that, when viewed from a human activity basis, London is polycentric in its nature since this centrality radius captures multiple smaller centres as well as the core urban area. This outcome corresponds to the theories of multiple centralities proposed by Hillier (1999) that suggests London is comprised of a network of smaller and larger town centres across the city. Particularly important is using this finding to understand the spatial ordering of centres of pedestrian activity, and the scales at which they operate. When thinking of infrastructural development in the city, considering intensification of centres that are prominent at this scale of centrality would be an important starting point to enable development that satisfies the demonstrated spatial distribution of pedestrian demand. Even with all the advances in mobility technology it is evident that aggregate activity in London is still structured according to pedestrian principles of proximity, centrality and travel time. This highlights the paramount importance of considering pedestrian activity on an equal if not higher footing than other modes of travel and movement.

Research into the long-term success of many of London's smaller town centres shows that there is a demand for local centres which support a combination of short trips on foot and longer range trips by car and public transport (Carmona et al. 2015; Vaughan et al., 2010; Jones et al., 2007). Intensification of public transport accessibility, network connectivity and land use diversity around these centres would fulfil this demand. Furthermore, by developing active transport infrastructures within and between centres outside of the core urban area active travel could significantly increase in these areas. If the findings regarding the correspondence between highest closeness centrality at $2000 \mathrm{~m}$ and peaks of pedestrian activity can be replicated in other cities with comparable data, it will have important implications for urban planning, design and transport infrastructure planning, as well as the central role of pedestrians and their travel-time constraints in urban systems and their development

The methods and model presented in this paper have already been applied in current research into community severance (Mindell et al, 2012; Mindell et al, 2017). It has also been applied in work with Transport for London for strategic identification of locations where walking has the greatest potential to be increased by infrastructural or behavioural interventions. A subsequent study analyses relationships between areas of social and 
economic deprivation and potential pedestrian conflict with motorised transport modes. Central to this analysis is the flexibility of the built environment variables' construction at a fine-grained spatial scale that allows them to merge with various other datasets that have varying geographies, from individual roads to administrative areas. The ability of the approach to be used analytically in policy formation and evaluation in relation to active transport is important due to the long established analytical methods related to motorised transport that have long had the advantage of analytically based evaluation tools.

The application of modelling tools, such as those presented in this article, to urban planning and transport infrastructure development are centred on enabling understandings of the city as a set of interconnected and overlapping places and spaces. Understanding how cities work together through their spatial and built environment properties allows planning decisions to be taken that work alongside the pre-existing structure of the city. This can maximise the impact of interventions on making cities better places for walking and active travel, but also more capable of fulfilling their potential as successful urban places for the health and well-being of their inhabitants.

\section{Acknowledgements}

This paper was produced as a part of the Street Mobility and Network Accessibility research project, which is supported by the UK Engineering and Physical Sciences Research Council (EPSRC), Economic and Social Research Council (ESRC), and Arts and Humanities Research Council (AHRC) [grant number EP/K037323/1].

We would like to thank Transport for London for supplying the pedestrian density dataset that was used in this research and the other members of the Street Mobility and Network Accessibility project: Jennifer Mindell, Peter Jones, Muki Haklay, Nora Groce, Shaun Scholes, Paulo Anciaes and Jemima Stockton.

\section{References}

Anselin, L. (1995). "Local indicators of spatial association - LISA". Geographical Analysis, 27, 93-115.

Anselin, L. (2005). "Exploring Spatial Data with GeoDATM: A Workbook". Spatial Analysis

Laboratory. p. 138.

Buman, M. P., Hekler, E. B., Haskell, W. L., Pruitt, L., Conway, T. L., Cain, K. L., ... \& King, A. C. 2010. Objective light-intensity physical activity associations with rated health in older adults. American Journal of Epidemiology, 172(10), 1155-1165.

Carmona, M. 2015. London's local high streets: The problems, potential and complexities of mixed street corridors. Progress in Planning, 100, 1-84.

Catalina, T., Virgone, J., \& Blanco, E. (2008). Development and validation of regression models to predict monthly heating demand for residential buildings. Energy and buildings, 40(10), 1825-1832.

Cerin, E., Saelens, B. E., Sallis, J. F., \& Frank, L. D. (2006). Neighborhood Environment Walkability Scale: validity and development of a short form. Medicine and science in sports and exercise, 38(9), 1682.

Cervero, R., \& Kockelman, K. (1997). Travel demand and the 3Ds: density, diversity, and design. Transportation Research Part D: Transport and Environment, 2(3), 199-219.

Chiaradia, A. \& Koch, A. 2013. Urban Design Gold Dust. Urban Design (special issue on the value of urban design), 126, 15-17.

Feng, J., Glass, T. A., Curriero, F. C., Stewart, W. F., \& Schwartz, B. S. (2010). The built environment and obesity: a systematic review of the epidemiologic evidence. Health \& place, 16(2), 175-190.

Florida, R. 2005. Cities and the creative class, Routledge.

Forsyth, A. \& Southworth, M. 2008. Cities Afoot - Pedestrians, Walkability and Urban Design. Journal of Urban Design, 13, 1-4.

Frank, L. D., \& Pivo, G. 1994. Impacts of mixed use and density on utilization of three modes of travel. Transportation research record, 44-44.

Frank, L. D., Sallis, J. F., Saelens, B. E., Leary, L., Cain, K., Conway, T. L. \& Hess, P. M. 2010. The development of a walkability index: application to the Neighbourhood Quality of Life Study. British Journal of Sports Medicine, 44, 924-933. 
Frank, L. D., Schmid, T. L., Sallis, J. F., Chapman, J. \&Saelens, B. E. 2005. Linking objectively measured physical activity with objectively measured urban form - Findings from SMARTRAQ. American Journal of Preventive Medicine, 28, 117-125.

Freeman, L. C. 1977. A set of measures of centrality based on betweenness. Sociometry, 35-41.

Freeman, L., Neckerman, K., Schwartz-Soicher, O., Quinn, J., Richards, C., Bader, M. D., ... \& Arno, P. 2013. Neighborhood walkability and active travel (walking and cycling) in New York City. Journal of Urban Health, 90(4), 575-585.

Giles-Corti, B., Timperio, A., Bull, F. \& Pikora, T. 2005. Understanding physical activity environmental correlates. Exerc Sport Sci Rev, 33, 175-81.

Glazier, R. H., Creatore, M. I., Weyman, J. T., Fazli, G., Matheson, F. I., Gozdyra, P., Moineddin R., Kaufman-Shriqui V. \& Booth, G. L. (2014). Density, destinations or both? A comparison of measures of walkability in relation to transportation behaviors, obesity and diabetes in Toronto, Canada. PloS one, 9(1), e85295.

Grasser, G., D. Dyck, S. Titze and W. Stronegger. 2013. Objectively measured walkability and active transport and weight-related outcomes in adults: a systematic review. International Journal of Public Health 58(4): 615-625.

Hajna, S., Ross, N. A., Brazeau, A. S., Bélisle, P., Joseph, L., \& Dasgupta, K. (2015). Associations between neighbourhood walkability and daily steps in adults: a systematic review and meta-analysis. BMC public health, 15(1), 768.

Heath, G. W., Brownson, R. C., Kruger, J., Miles, R., Powell, K. E., \& Ramsey, L. T. (2006). The effectiveness of urban design and land use and transport policies and practices to increase physical activity: a systematic review. Journal of Physical Activity and Health, 3(s1), S55-S76.

Hillier, B. 1999. Centrality as a process: accounting for attraction inequalities in deformed grids. Urban Design International, 4(3-4), 107-127.

Hillier, B. 1996.Cities as Movement Economies. Urban Design International, 1, 49-60.

Hillier, B. \& Hanson, J. 1984. The Social Logic of Space. CUP, Cambridge.

Hillier, B. \& lida, S. 2005.Network and Psychological Effects in Urban Movement. Lecture Notes in Computer Science.3693 ed. Springer Berlin / Heidelberg: Springer.

Hillier, B., Penn, A., Hanson, J., Grajewski, T. \& Xu, J. 1993. Natural Movement: or configuration and attraction in urban pedestrian movement. Environment and Planning B: 20, 29-66.

Jones, P., Roberts, M. \& Morris, L. 2007. Rediscovering mixed-use streets: the contribution of local high streets to sustainable communities. London: Polity Press.

Karimi, K. 2012. A configurational approach to analytical urban design: 'Space syntax' methodology. Urban Design International, 17, 297-318.

Koohsari, M. J., Kaczynski, A. T., Giles-Corti, B. \& Karakiewicz, J. A. 2013. Effects of access to public open spaces on walking: Is proximity enough? Landscape and Urban Planning, 117, 92-99.

Lamíquiz, P. J. \& López-Domínguez, J. 2015. Effects of built environment on walking at the neighbourhood scale. A new role for street networks by modelling their configurational accessibility? Transportation Research Part A: Policy and Practice, 74, 148-163.

Law, S., Chiaradia, A. \& Schwander, A. 2012. Towards a multimodal space syntax analysis: A case study of the London street and underground network. Eighth International Space Syntax Symposium, Santiago, Chile, 8021-20.

Leslie, E., B. Saelens, L. Frank, N. Owen, A. Bauman, N. Coffee and G. Hugo. 2005. "Residents' perceptions of walkability attributes in objectively different neighbourhoods: a pilot study." Health \& Place 11(3): 227-236.

Leslie, E., Coffee, N., Frank, L., Owen, N., Bauman, A., \& Hugo, G. (2007). Walkability of local communities: using geographic information systems to objectively assess relevant environmental attributes. Health \& place, 13(1), 111-122.

Lo, R. H. 2009. Walkability: what is it? Journal of Urbanism, 2, 145-166.

Marchetti, C. 1994. Anthropological invariants in travel behaviour. Technological forecasting and social change, 47(1), 75-88.

McCahil, C., \& Garrick, N. 2008. The applicability of space syntax to bicycle facility planning. Transportation Research Record, (2074), 46-51.

McGrath, L. J., Hopkins, W. G., \& Hinckson, E. A. (2015). Associations of objectively measured built-environment attributes with youth moderate-vigorous physical activity: a systematic review and meta-analysis. Sports medicine, 45(6), 841-865. 
Mindell, J., and Karlsen, S. 2012. Community Severance and Health: What Do We Actually Know? Journal of Urban Health:1-15.

Mindell J., Anciaes P., Dhanani A., Stockton J., Jones P., Haklay M., Groce N., Scholes S., \& Vaughan L. (2017) Using Triangulation to Assess a Suite of Tools to Measure Community Severance, Journal of Transport Geography (in press).

Moran, M., Van Cauwenberg, J., Hercky-Linnewiel, R., Cerin, E., Deforche, B., \& Plaut, P. 2014. Understanding the relationships between the physical environment and physical activity in older adults: a systematic review of qualitative studies. International Journal of Behavioral Nutrition and Physical Activity, 11(1), 79.

Moudon, A. V., C. Lee, A. O. Cheadle, C. Garvin, D. Johnson, T. L. Schmid, R. D. Weathers and L. Lin. 2006. Operational definitions of walkable neighbourhood: Theoretical and empirical insights. Journal of Physical Activity \& Health 3.

Moudon, A. V. \& Lee, C. 2003. Walking and bicycling: an evaluation of environmental audit instruments. American Journal of Health Promotion, 18, 21-37.

Oakes, J. M., Forsyth, A., \& Schmitz, K. H. 2007. The effects of neighbourhood density and street connectivity on walking behaviour. Epidemiologic Perspectives \& Innovations, 4(1), 16.

Ourghi, R., Al-Anzi, A., \& Krarti, M. 2007. A simplified analysis method to predict the impact of shape on annual energy use for office buildings. Energy Conversion and Management, 48(1), 300-305.

Oyeyemi, A. L., Conway, T. L., Adedoyin, R. A., Akinroye, K. K., Aryeetey, R., Assah, F., ... \& Lambert, E. V. (2016). Construct validity of the neighborhood environment walkability scale for Africa. Medicine and Science in Sports and Exercise. DOI. 10.1249/MSS.0000000000001131.

Renalds, A., Smith, T. H., \& Hale, P. J. 2010. A systematic review of built environment and health. Family \& community health, 33(1), 68-78

Sallis, J. F., Cervero, R. B., Ascher, W., Henderson, K. A., Kraft, M. K. \& Kerr, J. 2006.An ecological approach to creating active living communities. Annu. Rev. Public Health, 27, 297-322.

Sarkar, C., Gallacher, J. \& Webster, C. 2013. Built environment configuration and change in body mass index: The Caerphilly Prospective Study (CaPS). Health \& place.

Sarkar, C., Webster, C., Pryor, M., Tang, D., Melbourne, S., Zhang, X. \& Jianzheng, L. 2015. Exploring associations between urban green, street design and walking. Landscape and Urban Planning, 143, 112-125.

Schelling, T. (1969) "Models of segregation", American Economic Review, 1969, 59(2), 488493.

Song, Y. 2005. Smart growth and urban development pattern: A comparative study. International Regional Science Review, 28, 239-265.

Sundquist, K., Eriksson, U., Kawakami, N., Skog, L., Ohlsson, H., \& Arvidsson, D. (2011). Neighborhood walkability, physical activity, and walking behavior: the Swedish Neighborhood and Physical Activity (SNAP) study. Social science \& medicine, 72(8), 1266-1273.

Transport for London (2016) Travel in London: Report 9, TfL, London.

Turner, A. 2001.Depthmap (computer program) UCL. London.

Van Dyck, D., Cardon, G., Deforche, B., Sallis, J. F., Owen, N., \& De Bourdeaudhuij, I. (2010). Neighborhood SES and walkability are related to physical activity behavior in Belgian adults. Preventive medicine, 50, S74-S79.

Van Dyck, D., Cerin, E.,...Sallis, J. F. 2012. Perceived neighbourhood environmental attributes associated with adults' transport-related walking and cycling: Findings from the USA, Australia and Belgium. Int J Behav Nutr Phys Act, 9, 1-14.

Van Holle, V., B. Deforche, J. Van Cauwenberg, L. Goubert, L. Maes, N. Van de Weghe and I. De Bourdeaudhuij 2012. Relationship between the physical environment and different domains of physical activity in European adults: a systematic review. BMC Public Health 12(1): 807.

Van Holle, V., Van Cauwenberg, J., Van Dyck, D., Deforche, B., Van de Weghe, N., \& De Bourdeaudhuij, I. 2014. Relationship between neighborhood walkability and older adults' physical activity: results from the Belgian Environmental Physical Activity Study in Seniors (BEPAS Seniors). International journal of behavioral nutrition and physical activity, 11(1), 110.

Vaughan, L., Jones, C. E., Griffiths, S., \& Haklay, M. 2010.The spatial signature of suburban 
town centres. The Journal of Space Syntax, 1(1), 77-91.

Vaughan, L., Dhanani, A. \& Griffiths, S. 2013. Beyond the suburban high street cliché - a study of 150 years of London's network adaptation to change. Journal of Space Syntax, 4, 221-241.

Volchenkov, D., \& Blanchard, P. 2008. Scaling and universality in city space syntax: between

Zipf and Matthew. Physica A: Statistical Mechanics and its Applications, 387(10), 2353-2364.

Wegener, M., \& Fürst, F. 2004. Land-use transport interaction: state of the art.

Wegener, M. 2014. Land-use transport interaction models. In Handbook of Regional Science (pp. 741-758). Springer Berlin Heidelberg. 